\title{
Isolasi dan Identifikasi Senyawa Geraniol dari Minyak Atsiri Tanaman Sereh Wangi Cymbopogon nardus (L) Rendle
}

\section{(Isolation and Identification of Geraniol Compounds from The Essential Oil of Cymbopogon nardus (L) Rendle)}

\author{
SHIRLY KUMALA ${ }^{5 *}$, YELFI ANWAR ${ }^{1,2}$, ELVINA DHIAUL IFTITAH ${ }^{3}$, PARTOMUAN \\ SIMANJUNTAK ${ }^{4,5}$ \\ ${ }^{1}$ Program Doktoral, Fakultas Farmasi, University Pancasila, Jakarta. \\ ${ }^{2}$ Fakultas Farmasi, Universitas 17 August 1945, Jakarta. \\ ${ }^{3}$ Departemen Kimia, Fakultas Matematika dan Ilmu Pengetahuan Alam, Universitas Brawijaya, \\ Malang. \\ ${ }^{4}$ Pusat Penelitian Bioteknologi, Lembaga Ilmu Pengetahuan Indonesia. \\ ${ }^{5}$ Fakultas Farmasi, Universitas Pancasila, Jakarta. \\ *Penulis korespondensi, Hp : 08129026821 \\ e-mail: fskumala@univpancasila.ac.id
}

Diterima 28 Maret 2019, Disetujui 2 Oktober 2019

\begin{abstract}
Abstrak: Indonesia merupakan negara penghasil utama beberapa minyak atsiri seperti minyak sereh, minyak cengkeh, minyak kenanga, minyak akar wangi, minyak cendana, dan minyak nilam. Genus Cymbopogon (Poaceae) memiliki komponen minyak esensial yang paling penting yaitu citral, geraniol, sitronelol, sitronelal. Geraniol adalah salah satu senyawa kimia yang paling penting dalam industri aroma, wewangian, menunjukkan sifat insektisida dan penolak serangga alami yang menunjukkan toksisitas rendah serta kelas baru agen kemoprevensi untuk kanker, antimikroba, antioksidan, antiinflamasi, beberapa efek vaskular, penambah penetrasi penghantaran obat transdermal. Penelitian ini bertujuan untuk mendapatkan senyawa geraniol yang diperoleh dari Cymbopogon nardus (L.) Rendle dan identifikasinya. Minyak atsiri sereh wangi diperoleh dari tanaman Cymbopogon nardus (L) Rendle dengan menggunakan metode destilasi uap-air, lalu dilakukan proses fraksinasi dan dilanjutkan proses isolasi dan pemurnian dengan kromatografi kolom dan diperoleh senyawa murni dari fraksi 5. Berdasarkan interpretasi data IR, Resonansi magnet Inti (RMI proton dan karbon) dan spektra massa (GC-MS) untuk isolate dari fraksi 5 ditetapkan sebagai senyawa geraniol. Geraniol dari minyak atsiri tanaman sereh wangi Cymbopogon nardus (L) Rendle dapat diperoleh dengan metode destilasi uap-air, fraksinasi dan isolasi
\end{abstract}

Kata kunci: Cymbopogon nardus (L) Rendle, geraniol, kromatografi kolom, minyak atsiri, NMR.

\begin{abstract}
Indonesia is a major producer of several essential oils such as citronella oil, clove oil, cananga oil, vetiver oil, sandalwood oil, and patchouli oil. The Cymbopogon (Poaceae) genus has the most important components of essential oils, namely citral, geraniol, citronellol, citronellal. Geraniol is one of the most important chemical compounds in the aroma and fragrance industry and shows the nature of insecticides and natural insect repellents which show low toxicity and is suggested to represent a new class of chemoprevention agents for cancer, antimicrobial, anti-oxidant, anti-inflammatory and some vascular effects Transdermal drugs also attract the attention of researchers and scientists in the field of formulation. This study aimed to obtain geraniol compounds obtained from Cymbopogon nardus (L.) Rendle and identification. The citronella, essential oil was obtained from the Cymbopogon nardus (L) Rendle plant using a water-steam distillation method, then fractionation was carried out and continued by purification isolation by column chromatography. Based on the interpretation of IR data, Core magnetic resonance (proton and carbon RMI) and mass spectra for isolate 5 were determined as geraniol compounds. Geraniol can be obtained from Cymbopogon nardus (L) Rendle plants by watersteam distillation, fractionation and isolation methods.
\end{abstract}

Keywords: Chromatography colomn, Cymbopogon nardus (L) Rendle, geraniol, essential oil, NMR 


\section{PENDAHULUAN}

SALAH satu minyak atsiri yang dihasilkan dan dijadikan sumber devisa adalah minyak sereh wangi. Menurut data dari Departemen Kementrian Perdagangan Ekspor Non Migas periode 2013 - 2018, tren ekspor minyak atsiri 2013 - 2017 meningkat sebesar 4\% dan perubahan 2018/2017 adalah $19,85 \%{ }^{(1)}$.

Ganjewala melaporkan bahwa genus Cymbopogon (Poaceae) memiliki komponen minyak esensial yang banyak digunakan sebagai perasa, wewangian, kosmetik, sabun dan deterjen karena aroma khas lemon dan rose-like. Signifikansi aktivitas biologis dan farmakologis dari minyak esensial ini telah berkembang pesat dalam sepuluh tahun terakhir yaitu sebagai anti-inflamasi, antikanker, allelopati, penguraian radikal bebas dan aktivitas biologis lain serta penerapan penting industri terutama pada kemasan makanan ${ }^{(2)}$.

Telah dilaporkan destilasi uap - air minyak atsiri Cymbopogon nardus (Linn.) Rendle (Syn Andropogon nardus Linn.), mengandung bebarapa komponen. Monoterpen yang menonjol adalah sitronelal $(27,87 \%)$, geraniol $(22,77 \%)$, geranial $(14,54 \%)$, sitronelol $(11,85 \%)$ dan neral $(11,21 \%)^{(3)}$.

Chen (2010) melaporkan geraniol adalah alkohol terpen komersial yang penting pada minyak esensial beberapa tanaman aromatik. Selain aroma yang menyenangkan, geraniol diketahui menunjukkan sifat insektisida, penolak serangga dan digunakan sebagai agen pengendali hama alami yang menunjukkan toksisitas rendah, serta disarankan mewakili kelas baru agen kemoprevensi untuk kanker, antimikroba, anti oksidan, antiinflamasi dan beberapa efek vaskular juga telah diselidiki ${ }^{(4)}$. Efek geraniol sebagai penambah penetrasi penghantaran obat transdermal juga menarik perhatian peneliti dan ilmuwan di bidang formulasi ${ }^{(5)}$. Aktivitas biosidalnya (bakterisidal, virisida dan fungisida) bahkan terhadap bakteri multi-resisten, juga bisa memberikan kenyamanan jiwa bagi pasien berkat aroma yang menyenangkan, serta sebagai pengawet makanan juga telah dijelaskan ${ }^{(6,7)}$. Selanjutnya, EO telah digunakan untuk melawan infeksi nosokomial, sebagai cairan pembersih untuk desinfeksi peralatan medis dan permukaan ${ }^{(8)}$ atau sebagai aerosol di ruang operasi dan ruang tunggu untuk membersihkan udara untuk membatasi kontaminasi ${ }^{(9)}$.

\section{BAHAN DAN METODE}

Jenis penelitian ini adalah eksperimental. Minyak atsiri Cymbopogon nardus (L.) Rendle diperoleh dari tanaman sereh wangi Cymbopogon nardus (L.) Rendle yang ada di kebun percobaan Manoko, Lembang Bandung. Dilakukan proses destilasi, fraksinasi dan isolasi geraniol. Minyak atsiri, fraksi serta isolat yang diperoleh diidentifikasi dengan Kromatografi Lapis Tipis (KLT), Kromatografi Gas-Spektroskopi Massa (KG-MS); Gass Chromatography - Mass Spectroscopy (GC-MS) dan Nuclear Magnetic Reconancy (NMR).

BAHAN. Bahan yang digunakan pada tahap penelitian ini antara lain daun basah Cymbopogon nardus (L.) Rendle, aquades, silica gel, Etil Asetat, $\mathrm{N}-\mathrm{Hexane}$, plat KLT, geraniol standar diperoleh dari Shandong Nhu Pharmaceutical Co., Ltd .

Alat Penelitian. Peralatan yang digunakan dalam penelitian adalah peralatan gelas destilasi uap-air, GCMS merk Shimadzu GC-2010 Plus series (fase gerak : Helium; Fase diam : RT-5MS, $30 \mathrm{~mm}$ x 0,15 m ID x $0,25 \mu \mathrm{m}$ ), Infra merah merek FT-IR Perkin Elmer Spectrum, One, spectrometer NMR-JEOL JNM A $5000500 \mathrm{Mhz}(1 \mathrm{H})$; dan $125 \mathrm{MHz}$ (13C).

METODE. Minyak atsiri Cymbopogon nardus (L.) Rendle yang diperoleh dari tanaman sereh wangi yang ada di kebun percobaan Manoko - Lembang, Bandung, diekstraksi dengan metode destilasi, proses destilasi dilakukan selama 7-8 jam. Daun tanaman sereh wangi yang digunakan sebanyak $750 \mathrm{~kg}$. Dari hasil determinasi tanaman tersebut adalah tanaman sereh wangi (Cymbopogon nardus (L.) Rendle). Minyak atsiri yang dihasilkan dengan rendemen 1 $\%(7,50 \mathrm{~L})$. Berbeda dengan yang dilaporkan oleh Hamzah dkk (2014), perolehan rendemen sebesar $1.69 \%{ }^{(10)}$. Hal ini dapat dipengaruhi oleh beberapa faktor antara lain desain alat yang digunakan, panas dan waktu yang digunakan untuk mencapai titik didih, dsb. Komponen senyawa kimia yang terdapat dalam minyak atsiri sereh wangi dapat dilihat pada tabel 1. Kemudian dilakukan proses fraksinasi dan isolasi dengan menggunakan kromatografi kolom. Isolat yang diperoleh diidentifikasi menggunakan Kromatografi Lapis Tipis (KLT), Kromatografi Gas-Spektroskopi Massa (KG-MS), IR dan Nuclear Magnetic Reconancy (NMR).

\section{HASIL DAN PEMBAHASAN}

Destilasi Minyak Atsiri Sereh Wangi. Hasil analisis GC-MS pada Tabel 1. terlihat bahwa minyak atsiri sereh wangi Cymbopogon nardus (L) Rendle mengandung citronellal $(35,72 \%)$, Citronelol $(15,09 \%)$, geraniol $(12,89 \%)$, linalool $(1,2 \%)$, alpha terpineol $(0,11)$. Hasil ini sama dengan yang pernah dilaporkan oleh wany dkk (2013) dan Riyanto dkk 
$(2016)^{(11,12)}$.

Tabel 1. Komponen minyak atsiri sereh wangi Cymbopogon nardus (L) Rendle.

\begin{tabular}{clcccc}
\hline No & Komponen & R Time & Area & \% Area & SI \\
\hline 1 & Beta Myrcene & 9,188 & 3421822 & 0,09 & 97 \\
2 & D Limonene & 10,413 & 149518476 & 3,78 & 96 \\
3 & Linalool & 12,548 & 47311656 & 1,2 & 97 \\
4 & Citronelal & 15,164 & 1413835087 & 35,72 & 96 \\
5 & Alpha Terpineol & 16,458 & 4265735 & 0,11 & 97 \\
6 & Citronelol & 18,568 & 597470174 & 15,09 & 98 \\
7 & Geraniol & 19,579 & 510353648 & 12,89 & 93 \\
8 & Eugenol & 22,146 & 15136864 & 0,38 & 96 \\
9 & Geranyl Acetat & 22,647 & 118741291 & 3 & 96 \\
10 & Caryophyllene & 23,480 & 77586083 & 1,96 & 95 \\
11 & Copaene & 24,004 & 21591156 & 0,55 & 89 \\
12 & Germacrene & 24,004 & 21591156 & 0,55 & 94 \\
13 & Alpha Cadinol & 27,195 & 24411977 & 0,62 & 92 \\
\hline
\end{tabular}

Fraksinasi Minyak Atsiri Sereh Wangi. Proses fraksinasi minyak sereh wangi dapat di lihat pada Gambar 1. $150 \mathrm{~mL}$ minyak atsiri Sereh Wangi Cymbopogon nardus (L) Rendle dilakukan selama 12 jam. Dengan menggunakan vakum pada tekanan $30 \mathrm{mmHg}$. Diperoleh geraniol pada fraksi 5 dengan range suhu $227-240^{\circ} \mathrm{C}$, rasio refluk $20: 1$, Temperatur labu $104,9^{\circ} \mathrm{C}$, Temperatur vapor $30,1^{\circ} \mathrm{C}$, Temperatur condensor $23{ }^{\circ} \mathrm{C}$ dengan rendemen $36 \%$ $(54 \mathrm{~mL})$. Proses fraksinasi ini berbeda dengan yang dilaporkan oleh Egi Agustian dkk, geraniol dapat

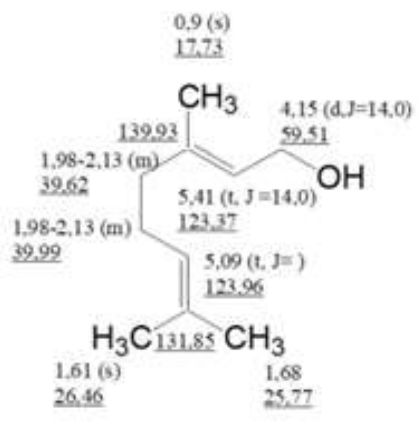

\section{Gambar 1. Struktur kimia geraniol berdasarkan} spektra 1 H dan 13 C-NMR.

difraksinasi pada suhu $133,7^{\circ} \mathrm{C}$, perolehan geraniol dari minyak sereh wangi (geraniol $=20.54 \%$ ) pada fraksi 3, pada tekanan $30 \mathrm{mmHg}$, tekanan vacum 60 mmHg, dengan rasio refluk $20: 10$ adalah $47,88 \%{ }^{(13)}$. Hal ini disebabkan oleh beberapa faktor antara lain jenis peralatan yang digunakan, metode fraksinasi yaitu tekanan, rasio refluks, $\mathrm{T}$ labu, $\mathrm{T}$ puncak yang digunakan. Perolehan hasil fraksinasi (sampel $150 \mathrm{~mL}$ minyak atsiri sereh wangi) dapat dilihat pada Tabel 2. Senyawa-senyawa yang terdapat pada fraksi 5 dapat di lihat pada Tabel 3 .

Tabel 2. Perolehan hasil fraksinasi (sampel $150 \mathrm{~mL}$ minyak atsiri sereh wangi).

\begin{tabular}{|c|c|c|c|}
\hline $\begin{array}{l}\text { No } \\
\text { Fraksi }\end{array}$ & $\begin{array}{l}\text { Range Suhu } \\
\left({ }^{\circ} \mathrm{c}\right)\end{array}$ & $\begin{array}{l}\text { Volume } \\
\text { Fraksi } \\
(\mathrm{Ml}(\%))\end{array}$ & $\begin{array}{l}\text { Komponen Mayor } \\
\left(\mathrm{Td}\left({ }^{\circ} \mathrm{c}\right), \% \text { Area }\right)\end{array}$ \\
\hline 1 & $156-180$ & $4(2,7)$ & $\begin{array}{l}\text { A-Pinene }(156: \\
0,09) \\
\text { ß-Myrcene }(167: \\
1,25) \\
\text { D-Limonene }(177 \\
: 39,28)\end{array}$ \\
\hline 2 & $180-200$ & $4(2,7)$ & $\begin{array}{l}\text { D-Limonen }(177: \\
16,68) \text { Linalool } \\
(198-200: 1,84)\end{array}$ \\
\hline 3 & $200-220$ & $68(45,33)$ & $\begin{array}{l}\text { Citronelal (205: } \\
77,77) \\
\text { Linalool }(198- \\
200: 1,06)\end{array}$ \\
\hline 4 & $220-227$ & $4(2,7)$ & $\begin{array}{l}\text { Citronelol ( } 225: \\
23,24) \text { Terpineol } \\
(218-219: 1,17)\end{array}$ \\
\hline 5 & $227-240$ & $54(36)$ & $\begin{array}{l}\text { Citronelol (225: } \\
26,68) \\
\text { Geraniol }(230: \\
0,06)\end{array}$ \\
\hline \multirow[t]{2}{*}{6} & $240-300$ & $2(1,33)$ & $\begin{array}{l}\text { B-Elemene }(0,2) \\
\text { Spathulenol }(0,2)\end{array}$ \\
\hline & Residu & $25(16,67)$ & \\
\hline
\end{tabular}


Tabel 3. Komponen fraksi 5.

\begin{tabular}{cccccc}
\hline No & Komponen & R Time & Area & \% Area & SI \\
\hline 1 & Beta-Myrcene & 7,341 & 7988576 & 0,04 & 95 \\
2 & Citronellal & 8,670 & 5706828 & 0,03 & 96 \\
3 & D-Limonene & 8,999 & 97560553 & 0,46 & 96 \\
4 & Beta-Myrcene & 9,487 & 29390062 & 0,14 & 97 \\
5 & Geraniol & 9,755 & 11947526 & 0,06 & 89 \\
5 & D-Limonene & 10,718 & 200018952 & 0,94 & 96 \\
6 & DL-Isopulegol & 16,910 & 783730039 & 3,67 & 94 \\
\hline
\end{tabular}

Isolasi Geraniol dari Fraksi 5. Untuk mendapatkan geraniol maka dilakukan isolasi dari fraksi $5(45 \mathrm{~mL})$ dengan menggunakan metode kromatografi kolom ${ }^{(14)}$. Eluen yang digunakan adalah N-Hexane : Etil Asetat (10:1). Hasil proses isolasi diperoleh fraksi 40 sampai dengan fraksi 65 memiliki spot yang sama dengan spot geraniol standar $(\mathrm{Rf}=$ 0.35). Fraksi 40 sampai dengan fraksi 65 digabung lalu digunakan sebagai sampel untuk proses identifikasi dengan NMR. Diperoleh rendemen isolat geraniol sebanyak $0,02 \%$ yaitu $1,042 \mathrm{~g}$ dari $50 \mathrm{~mL}$ fraksi 5 . Berbeda dengan yang dilakukan oleh Daniel dkk (2015) yang telah berhasil memisahkan geraniol dari sitronelol melalui pengoksidaan geraniol menjadi geranial. Oksidasi selektif (hidrogen peroksida yang diaktifkan oleh platinum hitam) dari geraniol (dalam rhodinol) menjadi geranial. Hasil yang diperoleh adalah $81 \%$ geranial. Pemurnian menggunakan distilasi fraksional dilakukan untuk mendapatkan geraniol murni dan menghilangkan fraksi minor sitronelal $^{(15)}$. Demikian juga isolasi geraniol yang dilakukan oleh Siwi dkk ${ }^{(13)}$.

Analisis Resonansi Magnetik Inti (RMI Proton dan Karbon) untuk Isolat Murni. Hasil analisis spektrum RMI Proton untuk isolat murni menunjukkan bahwa pergeseran kimia untuk metil $\left(-\mathrm{CH}_{3}\right)$ terdapat pada $\delta \mathrm{H} 1,62\left(\mathrm{~s}, \mathrm{CH}_{3} \mathrm{H}-10\right) ; 1,68$ (s, 2 x CH3; H-8, H-9); gugus metilen (CH2) terdapat pada $\delta \mathrm{H} \mathrm{1,98} \mathrm{2,13} \mathrm{(m;2,13} \mathrm{Hz;} \mathrm{H-4,} \mathrm{H-9);} \delta \mathrm{H} \mathrm{4,15}$ ppm (t, J=6 Hz; H-6), 5,41 (t, J=14 Hz, H-2; 4,15 (d, $\mathrm{J}=14 ; \mathrm{H}-1)$. Pergeseran kimia senyawa isolat dapat di lihat pada Tabel 4. Spektrum RMI Proton dapat dilihat pada Gambar 2. Hasil analisis RMI karbon menunjukkan bahwa terdapat 10 signal karbon yang terdiri dari 3 karbon untuk $-\mathrm{CH}_{3}(\delta \mathrm{C} 17,73 ; 25,77$; 26,46), 3 karbon untuk $-\mathrm{CH}_{2}(\delta \mathrm{C} 39,62 ; 39,99 ; 59,51)$, 4 karbon untuk alkena $(\delta \mathrm{C} 123,37 ; 139,93 ; 131,85$; 123,96). Spektrum RMI karbon dapat dilihat pada Tabel 4 dan Gambar 3. Hasil analisis spektra infra merah (IR) menunjukkan adanya gugus hdroksil pada bilangan gelombang $3450 \mathrm{~cm}^{-1}$; alkena/alkane pada bilangan gelombang $2900 \mathrm{~cm}^{-1}$. Data spektra MS (LC-MS) memberikan m/z 154 untuk rumus molekul $\mathrm{C}_{10} \mathrm{H}_{18} \mathrm{O}$. Berdasarkan perbandingan pergeseran kimia RMI proton dan karbon antara senyawa isolat dengan senyawa geraniol pada literatur, maka struktur kimia untuk isolate fraksi dapat ditetapkan sebagai geraniol (Gambar 1).

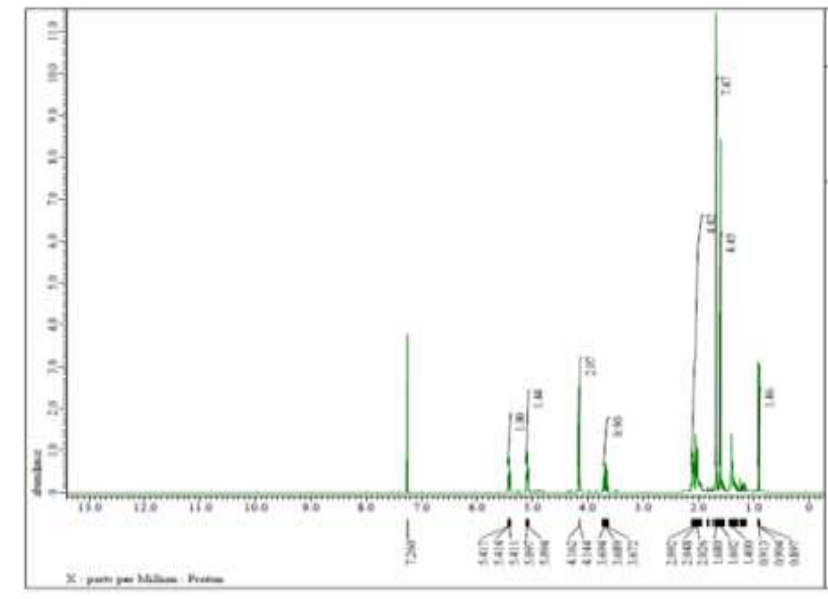

Gambar 2. Spektra 1H-NMR isolat Fraksi 5 minyak atsiri Cymbopogon nardus (L.) Rendle.

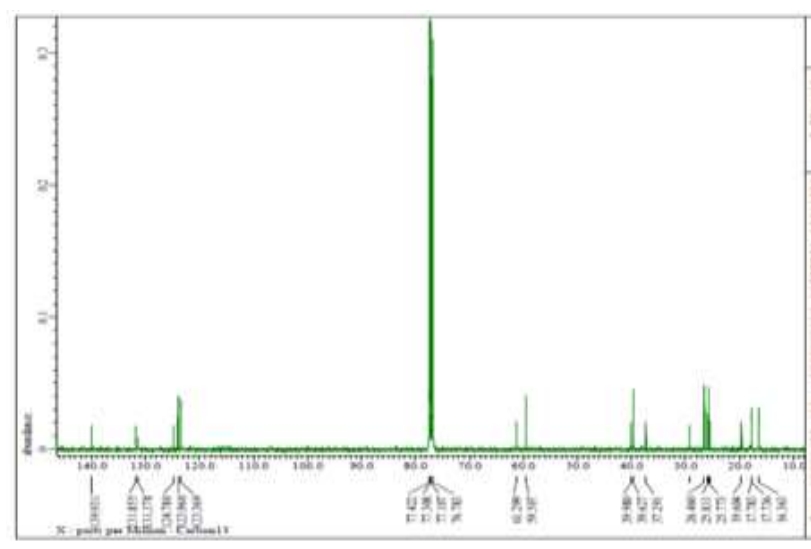

Gambar 3. Spektra 1C-NMR isolat Fraksi 5 minyak atsiri Cymbopogon nardus (L.) Rendle 
Tabel 4. Pergeseran kimia untuk senyawa isolat fraksi 5.

\begin{tabular}{cllcc}
\hline No & \multicolumn{1}{r}{$\Delta$ H Isolat } & \multicolumn{1}{c}{ Literatur $(16)$} & $\Delta$ C Isolat & Literatur(16) \\
\hline 1 & $4,15(\mathrm{D}, \mathrm{J}=14,0)$ & $4,15 \sim 4,16(2 \mathrm{H}, \mathrm{D})$ & 59,51 & 59,3 \\
2 & $5,41(\mathrm{~T}, \mathrm{~J}=14,0)$ & $5,40-5,43(1 \mathrm{H}, \mathrm{M})$ & 123,37 & 123,3 \\
3 & - & - & 139,93 & 139,7 \\
4 & $1,98-2,13(\mathrm{M})$ & $2,09 \sim 2,11(2 \mathrm{H}, \mathrm{D})$ & 39,62 & 39,5 \\
5 & $1,98-2,13(\mathrm{M})$ & $2,02 \sim 2,03(2 \mathrm{H}, \mathrm{D})$ & 39,92 & 39,5 \\
6 & $5,09(\mathrm{~T}, \mathrm{~J}=6,0)$ & $5,10(1 \mathrm{H}, \mathrm{M})$ & 123,96 & 123,9 \\
7 & - & - & 131,85 & 131,7 \\
8 & $1,68(\mathrm{~S})$ & $1,61(3 \mathrm{H}, \mathrm{S})$ & 26,46 & 26,4 \\
9 & 1,68 & $1,68 \sim 1,69(3 \mathrm{H}, \mathrm{T})$ & 25,77 & 25,6 \\
10 & $0,9(\mathrm{~S})$ & $1,40(3 \mathrm{H}, \mathrm{T})$ & 17,73 & 17,6 \\
\hline
\end{tabular}

\section{SIMPULAN}

Senyawa geraniol dari tanaman Cymbopogon nardus (L.) Rendle (12.89\%) dapat diperoleh dengan menggunakan metode destilasi, fraksinasi dan isolasi dengan kromatografi kolom. Berdasarkan perbandingan pergeseran kimia RMI proton dan karbon antara senyawa isolat fraksi 5 dengan senyawa geraniol pada literatur mempunyai kemiripan yang sama. Sehingga senyawa isolat fraksi 5 adalah geraniol.

\section{DAFTAR PUSTAKA}

1. Anonim.http://www.kemendag.go.id/id/economicprofile/indonesia-export-import/growth-of-nonoil-and-gas-export-commodity. Diakses tanggal 2 Februari 2019

2. Ganjewala D, 2009, Cymbopogon essential oils, Chemical compositions and bioactivities. Int J Essent Oil Ther. 56-65.

3. De Toledo LG, Dos Santos Ramos MA, Spósito L, Castilho EM, Pavan FR, De Oliveira Lopes É, et al, 2016, Essential oil of Cymbopogon nardus (L.) Rendle: A strategy to combat fungal infections caused by Candida species. Int J Mol Sci.;17(8).

4. Chen W, Viljoen AM, 2010, Geraniol - A review of a commercially important fragrance material. South African J Bot [Internet]. 76(4):643-51. Available from: http://dx.doi.org/10.1016/j.sajb.2010.05.008

5. Chen W, Viljoen AM, 2010, Geraniol - A review of a commercially important fragrance material. South African J Bot [Internet].;76(4):643-51. Available from: http://dx.doi.org/10.1016/j.sajb.2010.05.008

6. Singh BR, Agrawal R, Bhardwaj M, Dubey S, 2015, Clinical \& Medical Biochemistry : Open Access Antimicrobial Activity of Citronella Essential Oil on
Antimicrobial Drug Resistant Bacteria from Veterinary Clinical Cases, 1(1):1-9.

7. Oliveira MMM de, Brugnera DF, Cardoso M das G, Alves E, Piccoli RH, 2010, Disinfectant action of Cymbopogon sp. essential oils in different phases of biofilm formation by Listeria monocytogenes on stainless steel surface. Food Control.;21(4):549-53.

8. Warnke PH, Becker ST, Podschun R, Sivananthan S, Springer IN, Russo PAJ, et al, 2009, The battle against multi-resistant strains: Renaissance of antimicrobial essential oils as a promising force to fight hospitalacquired infections, J Cranio-Maxillofacial Surg, 37(7):392-7.

9. Baser, K.H.C. GB, 2010, Handbook Of Essential Oils, Science, Technology And Applications, United States Of America: CRC Press, Taylor \& Francis Group.

10. Hamzah MH, Che Man H, Abidin ZZ, Jamaludin H, 2014, Comparison of citronella oil extraction methods from Cymbopogon nardus grass by ohmic-heated hydro-distillation, hydro-distillation, and steam distillation, BioResources, 9(1):256-72.

11. Pattusamy V, Nandini N, Vijay M, Bheemappa K, 2013, Chemical Analysis and Therapeutic Uses of Citronella Oil from Cymbopogon Winterianus : A Short Review, Int J Adv Res. 1(2320):77-82.

12. Riyanto R, Untari DT, Cahyandaru N. Isolation and Application of the Lemongrass Essential Oil of Cymbopogon Nardus L.as a Growth Inhibitor of Lichens on Stone Cultural Heritage. IOSR J Appl Chem [Internet]. 2016;09(09):109-17. Available from: http://iosrjournals.org/iosr-jac/papers/vol9-issue9/ Version-2/S090902109117.pdf

13. Siwi I R, Rusli M S AE, 2013, Pemisahan fraksi kaya sitronelal, sitronelol, dan geraniol minyak sereh wangi menggunakan distilasi fraksinasi vakum imastia rahma siwi, Teknol Dep Pertanian, Ind Pertanian, Fak Teknol.

14. Grice ID, Rogers KL, Griffiths LR, 2011, Isolation of bioactive compounds that relate to the anti-platelet activity of Cymbopogon ambiguus, Evidence-based Complement, Altern Med. 
15. Chong DJW, Latip JB, Hasbullah SAB, Sastrohamidjojo $\mathrm{H}, 2015$, Separation of geraniol from citronellol by selective oxidation of geraniol to geranial, Sains Malaysiana, 44(8):1183-8.

16. Jeon JH, Lee CH, Lee HS, 2009, Food Protective Effect of Geraniol and Its Congeners against Stored Food Mites, 72(7):1468-71. 